ECOLOGICA, Vol. 28, No 101 (2021), 50-56

https://doi.org/10.18485/ecologica.2021.28.101.9

Originalni naučni rad

UDC:502.131.1:338

502.174:646.26

\title{
Izazov funkcionisanja i razvoja malih i srednjih preduzeća u cirkularnoj ekonomiji
}

\section{The challenge of functioning and development of small and medium enterprises in the circular economy}

\author{
Anđelka Tripković ${ }^{,}$, Ljiljana Arsić ${ }^{2}$ Sanja Dobričanin ${ }^{3}$ \\ 1,2,3Univerzitet u Prištini s privremenim sedištem u Kosovskoj Mitrovici, Ekonomski fakultet, Kolašinska 156, \\ 38220 Kosovska Mitrovica \\ 1,2,3 University in Priština (temporary in Kosovska Mitrovica), Faculty of Economics, Kolašinska 156, \\ 38220 Kosovska Mitrovica
}

Rad primljen: 21.01.2021, Rad prihvaćen: 25.02.2021.

Sažetak: Cirkularna ekonomija je regenerativni privredni i poslovni model koji pozitivno utiče na sve vrste kapitala: društveni, prirodni, finansijski i ljudski. Osnovni cilj upotrebe cirkularne ekonomije je regeneracija devastiranih prirodnih resursa, zadržavanje sirovina u upotrebi i produženi životni vek proizvoda, primenom određenog dizajna koji omogućava da na kraju životnog veka proizvodi ne postaju otpad i doprinose zagađenju. U radu je analizirano preduzeće KNIToMANIA koje je primer podrške održivom razvoju Srbije kroz koncept cirkularne ekonomije. KNIToMANIA je ideja koja spaja tradicionalnu kreativnost pletenja autentičnu za ove prostore i ekološku korisnost. Pokretačka niz jeste želja da se spoje ekološki i socijalni element kako bi se preko proizvoda i radionica doprinelo podizanju svesti o problemima koji postoje u okviru zajednice. Naime, zadatak KNIToMANIE je postizanje samoodrživosti kako bi se ovo preduzeće kontinuirano razvijalo. Proizvodi se heklaju od iskorišćenih plastičnih kesa, a izrađuju ih, ili proizvode, starije osobe koje time direktno doprinose zaštiti životne sredine.

Ključne reči: cirkularna ekonomija, održivi razvoj, sektor malih i srednjih preduzeća (MSP), upravljanje otpadom.

\begin{abstract}
Circular economy is a regenerative economic and business model that positively affects all types of capital: social, natural, financial and human. The main goal of using a circular economy is the regeneration of devastated natural resources, retention of raw materials in use and extended product life, by applying a certain design that allows products not to become waste at the end of their life and contribute to pollution. The paper analyzes the company KNIToMANIA, which is an example of support for sustainable development of Serbia through the concept of circular economy. KNIToMANIA is an idea that combines traditional knitting creativity authentic to these spaces and ecological utility. The driving force is the desire to combine the environmental and social elements in order to contribute to raising awareness of the problems that exist within the community through products and workshops. Namely, KNIToMANIE's task is to achieve self-sustainability in order for this company to continuously develop. The products are crocheted from used plastic bags, and they are made of produces by the elderly, which thus directly contribute to the protection of the environment.
\end{abstract}

Keywords: circular economy, sustainable development, small and medium enterprises (SME) sector, waste management.

17orcid.org/0000-0002-3972-4933, e-mail: tripkovicananandjelka@gmail.com

2orcid.org/0000-0002-3582-8161, e-mail: ljiljana.arsic@pr.ac.rs

${ }^{3}$ orcid.org/0000-0003-1804-9374, e-mail: sanja.dobricanin@pr.ac.rs 


\section{UVOD / INTRODUCTION}

Životna sredina se menja, ali na žalost, te promene ne idu na bolje. Naprotiv, svedoci smo negativnog uticaja ljudskih aktivnosti po životnu sredinu, uz sve češću pojavu prirodnih katastrofa koje bi se mogle dovesti u direktnu vezu sa aktivnostima ljudi u gradovima i naseljima (Jović i dr., 2019). Kao najveći rizici u savremenom svetu jesu svakako oni koji se odnose na životnu sredinu, a među njima se izdvajaju: klimatkse promene, zatim ekstremni vremenski događaji, prirodne katastrofe, kao i izlivanje otrovnih materijala, radioaktivno zagađenje, itd. (Bogetić i dr., 2020).

U uslovima globalne ekonomske krize ljudi su navikli da žive u harmoniji sa linearnom ekonomijom gde se roba proizvodi od sirovina, ista se prodaje $u$ što većem broju, i na kraju se baca. Međutim, ovaj model više ne funkcioniše (Vukadinović, 2018). Današnja situacija koju karakterišu ograničeni resursi sa jedne strane, i neograničene ljudske potrebe sa druge strane, pravovremeno oslikava probleme sa kojima se sreće svetska populacija. Globalno zagrevanje kao i opadanje biodiverziteta znači da ćemo svesno morati da prestanemo sa korišćenjem nekih od prirodnih resursa. Budućnost sve više zahteva primenu savremenih metoda upravljanja otpadom (Vuković i dr., 2020).

Cirkularna ekonomija, kružna ekonomija ili zelena ekonomija odnosi se na deljenje proizvoda i kupovinu usluga, a ne dobara. Sve što je otpad u jednom procesu proizvodnje može se iskoristiti kao resurs $u$ nekom od narednih proizvodnih procesa, odnosno, količina otpada u proizvodnji i upotrebi robe je svedena na minimun (Topić, Biederman, 2015). Mnogi autori predlažu da evropske i nacionalne ekonomije svoj fokus usmere ka ozelenjavanju potrošačkih preferencija tržišnih lanaca vrednosti i kultura kompanija, i podržavaju prepoznavanje i implementaciju zelenih poslovnih modela malih i srednjih preduzeća (MSP-a). Mala i srednja preduzeća su i te kako svesna prednosti poboljšanja efikasnosti korišćenja resursa, čak i kada ih u praksi ne povezuju dovoljno sa konceptom cirkularne ekonomije.

Cilj rada jeste prikazivanje uspešnosti implementacije cirkularne ekonomije u MSP u našem neposrednom okruženju. Studija slučaja je urađena u preduzeću KNIToMANIA, Kruševac.

Hipoteze od kojih se polazi u radu jesu:

1. Uticaj cirkularne ekonomije na održivi razvoj malih i srednjih preduzeća je ogroman i uslov je njihovog opstanka i razvoja u modernoj ekonomiji.

2. Cirkularna ekonomija doprinosi ekonomskom rastu i otvaranju novih radnih mesta.
3. Cirkularna ekonomija doprinosi racionalnom korišćenju raspoloživih resursa.

4. Uvođenje cirkularne ekonomije može da stvori značajne socijalne i ekonomske koristi, ali je za to neophodno uspostavljanje održivog sistema upravljanja otpadom.

Cirkularna ekonomija (CE) je revolucionarni koncept XXI veka koji odgovara na globalnu krizu zagađenja. Prema Sauvé model cirkularne ekonomije pokušava da zameni ustaljeni model linearne ekonomije, kako bi se u budućnosti sprečilo dalje pogoršavanje ne samo u eksploataciji neobnovljivih prirodnih resursa, već i da bi se sprečilo dalje ugrožavanje životne sredine (Sébastien et al, 2015).

Ne postoji ustaljena definicija cirkularne ekonomije. Postoji mišljenje da bi svaka država ponaosob trebalo da definiše ovaj pojam i da ga prilagodi sopstvenom shvatanju i mogućnostima (Kirchhnerr et al., 2020). United Nations Environment Programme (UNEP) definiše cirkularnu ekonomiju kao ekonomiju koja doprinosi opštem dobru i društvenoj jednakosti, dok istovremeno znatno smanjuje rizike po životnu sredinu i dalje iskorišćavanje prirodnih resursa (Ghisellini et al., 2016).

Cilj cirkularne ekonomije jeste tranzicija i razvoj društva u društvo u kome je nastanak otpada sveden na minimum. Digitalizacija, korišćenje novih tehnologija i uvođenje inovacija mogu da ubrzaju i olakšaju proces uvođenja cirkularne ekonomije, gde bi se pored očuvanja životne sredine i resursa podigla i konkurentnost privrede na zavidnom nivou (Findačevska i dr., 2015). Bitno je naglasiti da se koncept cirkularne ekonomije može u manjem ili većem obimu primeniti i na nivou preduzeća, industrije, ali i samih gradova (Vinšalek Stipić, 2017). U literaturi se sreću brojni primeri prepreka i izazova koji mogu sprečiti ili opet usporiti implementaciju ovog poslovnog modela. Kada se govori o preprekama uglavnom se misli na nedostatak informacija i podataka, nedostatak naprednih tehnologija, loše sprovođenje zakona, loše rukovođenje, loše upravljanje razvojnom strategijom, i tome slično (Musu, 2010).

Životna sredina se posmatra kao ključni stejkholder u savremenim uslovima poslovanja, što zahteva ophođenje prema njoj kao prema ograničenom resursu, a istovremeno utiče i na druge prirodne resurse. Ubrzana eksploatacija neobnovljivih resursa dovela je do smanjenja njihove raspoloživosti, što se negativno odražava kako na ekonomsku aktivnost na globalnom nivou, tako i na socijalni mir (Janković i dr., 2020). Na osnovu ovoga, velika pažnja se usmerava na koncept održivog razvoja, kao jednog od načina za očuvanje sigurnosti $i$ bezbednosti životne sredine (Ministarstvo zaštite životne sredine, 2018). Jedan od osnovnih instrumenata za sprovo- 
đenje održivog razvoja, za zaštitu i očuvanje životne sredine, smanjenje siromaštva, za otvaranje novih ranih mesta ali i za pokretanje sveta u pravcu razvoja sa smanjenim nivoom emisija ugljen-dioksida je poslovni model cirkularne ekonomije (Mihajlović i dr., 2020). Smatra se da ako alati cirkularne ekonomije donose bolje rezultate u pravcu održivosti, tada cirkularna ekonomija postaje osnovna paradigma održivog razvoja.

\section{MATERIJALI I METODE / MATERIALS AND METHODS}

Mala i srednja preduzeća u savremenim uslovima poslovanja jesu okosnica razvoja privrede jedne zemlje, pri čemu doprinose i većoj i boljoj konkurentnosti ukupne nacionalne privrede. Sektor malih i srednjih preduzeća je veoma bitan segment srpske privrede, ali i jedan od najznačajnijih indikatora prosperiteta (Živković i dr., 2020). lako je sektor MSP najkonkurentniji deo privrede naše zemlje, neminovno je da on ipak zaostaje u odnosu na prosek EU. Nivo konkurentnosti sektora MSP Srbije zaostaje u odnosu na prosek EU-28, na šta ukazuje komparativna analiza osnovnih pokazatelja poslovanja. MSP su u Srbiji u 2016. godini zapošljavala u proseku 2,5 radnika po preduzeću (prosek EU-28 je 4,0 radnika), a produktivnost je 3,7 puta bila niža u odnosu na prosek EU-28 (UNDP, 2019). Mala i srednja eko-preduzeća predstavljaju ključne poluge u sistemu cirkularne ekonomije i programu održivog razvoja. Činjenica je da su mala i ekopreduzeća ili osobe koje učestvuju u društvenoekonomskoj aktivnosti koja se zasniva na principu kružnog sistema (smanjenje, ponovna upotreba i recikliranje) koji promoviše održivo korišćenje ekoloških resursa i funkcionišu u skladu sa razvojnim izazovima (Arsić i dr., 2020). Iz tog razloga se u ovom radu ispituju izazovi i mogućnosti malih i srednjih eko-preduzeća u cirkularnoj ekonomiji Srbije. Naša država nije još uvek u potpunosti prepoznala cirkularnu ekonomiju kao mogućnost budućeg razvoja. Srbija bi poslovnim modelom cirkularne ekonomije dobila pre svega šansu za razvoj, a njeni građani "zelena radna mesta", ekološku bezbednost, viši kvalitet vode i vazduha, i generalno, viši kvalitet života. Evidentno je da je neophodno strateško opredeljenje koje bi se sa državnog nivoa usmerilo ka lokalnim nivoima vlasti i koje bi uticalo na promenu mišljenja. Sa druge strane, možda je proces tranzicije ka cirkularnoj ekonomiji samo jedna površina, a da se ispod te ideje krije marketinška iluzija koja nas kolektivno usmerava ka tom pravcu. U Privrednoj komori Srbije formiran je Centar za cirkularnu ekonomiju kao prvi korak ka primeni ovog koncepta, i od tada se broj kompanija koje se bave prikupljanjem, trans- portom, tretmanom i reciklažom otpada znatno povećao (OEBS, 2020).

Nemačka organizacija za međunarodnu saradnju, poznata pod akronimom GIZ, aktivno radi $\mathrm{i}$ zalaže se za uvođenje koncepta cirkularne ekonomije u Srbiji, još od 2015. godine. U okviru projekta Upravljanje otpadom u kontekstu klimatskih promena, u saradnji sa Privrednom komorom Srbije, Ministarstvom zaštite životne sredine i 17 lokalnih samouprava sprovode se brojne aktivnosi čija je suština unapređenje sistema upravljanja otpadom u korelaciji sa principima cirkularne ekonomije. Aktivnosti međunarodne organizacije GIZ sa lokalnim samoupravama dovele su do malih ali krucijalnih pomaka (GIZ, 2019).

Podsticanje međuopštinske saradnje jeste jedan od važnih fokusa projekta, čime je podrška usmerena ka kreiranju regionalnih struktura u cilju upravljanja otpadom. Ekolozi savetuju pojedince da ukoliko misle da je problematika zagađivanja manje važna od ekonomije, neka probaju ne disati dok broje novac. Jedan od gradova koji aktivno sarađuje sa ovom organizacijom jeste i grad Kruševac koji pripada Rasinskom okrugu. Za realizaciju ovog istraživanja korišćen je materijal u vidu pre svega zakonskih propisa, strategija razvoja, dosadašnjih rezultata svetskih organizacija koje se bave zaštitom životne sredine, neposrednim intervjuom i anketom u konkretnom preduzeću KNIToMANIA iz Kruševca. U toku istraživanja su korišćene induktivno-deduktivne metode, metode analize (istraživanje i objašnjavanje putem raščlanjivanja složenih pojmova) i sinteze (putem sinteze jednostavnijih sudova uopšte), sa elementima specijalizacije i generalizacije, uz primenu relevantnih postupaka saznanja iz inostranih iskustava, kao i komparativne metode (upoređivanja istih ili srodnih pojava).

Strateški pristup ka cirkularnoj ekonomiji podrazumeva promenu načina na kome se do sada baziralo projektovanje, korišćenje sirovina i sama proizvodnja plastičnih proizvoda uz istovremeni razvoj svesti privrede i stanovništva u smislu adekvatnih promena u načinu korišćenja ovih proizvoda ali i postupanja sa njima $u$ trenutku njihovog odbacivanja nakon upotrebe. Odvojeno sakupljanje otpada, tj. primarna selekcija je osnova za postizanje ciljeva cirkularne ekonomije za plastiku. Plastika je vredan materijal koji pokriva širok spektar primena u svakodnevnom životu, i koji se nalazi svuda, od domaćinstava do industrija. Često se dešava da je upotreba plastike efikasnija od drugih materijala (metala, stakla, drveta), što implicira da je ona tokom decenija doživela veliku ekspanziju. Ne samo da su troškovi proizvodnje postali niži zahvaljujući energetskoj efikasnosti, već je i sam materijal lakši od alternativnih materijala i manje je podložan ošte- 
ćenjima od hemijskih reakcija, kao što su rđanje ili oksidacija. Zabrana Kine da uvozi plastični otpad iz zapadnih zemalja uticala je višestruko na zemlje EU da unaprede zakonodavni okvir koji se odnosi na plstični otpad i cirkularnu ekonomiju. Kina koja je vodeći globalni uvoznik platičnog otpada (51\% ukupnog svetskog uvoza plastike 2014. godine) je januara 2018. godine uvela zabranu uvoza plastičnog otpada iz zapadnih zemalja. Naime, izvoz plastičnog otpada iz EU u Kinu je opao sa 1,6 miliona tona 2016. godine, na manje od 0,15 miliona tona 2018 . godine (UNDP, 2019).

Strateški pristup ka cirkularnoj ekonomiji podrazumeva promenu načina na kome se do sada baziralo projektovanje, korišćenje sirovina i proizvodnja plastičnih proizvoda uz istovremeni razvoj svesti privrede i stanovništva u smislu adekvatnih promena u načinu korišćenja ovih proizvoda ali i postupanja sa njima $u$ trenutku njihovog odbacivanja nakon upotrebe. Odvojeno sakupljanje otpada, tj. primarna selekcija je osnova za postizanje ciljeva cirkularne ekonomije za plastiku (Tabela 1).
Shvatajući ozbiljno probleme koje plastične kese izazivaju, svet preduzima i određene mere da ih smanji. Afrički kontinent je vodeći u pogledu svesti o negativnim posledicama upotrebe plastičnih kesa po životnu sredinu. Čak 15 afričkih zemalja je uvelo ili zabranu upotrebe plastičnih kesa ili taksu na njihovu upotrebu. To su Kenija, Mali, Kamerun, Tanzanija, Uganda, Etiopija, Malavi, Maroko, Južna Afrika, Ruanda i Bocvana. Ni Azija nije u velikom zaostatku. Kina je za vreme Olimpijskih igara 2008. godine zabranila proizvodnju tankih plastičnih kesa, a na velike kese je uvela taksu. U Australiji plastične kese nisu zabranjene, ali na određenim delovima teritorije su obeleženi prostori gde se kese odlažu. Određene oblasti Severne Amerike se bore protiv plastičnih kesa zabranom, taksama, ali i reciklažom. Neke države Južne Amerike takođe imaju svest o ovom problemu, a sa njim se bore proizvodnjom biorazgradivih kesa ili reciklažom. Stanje u Republici Srbiji prikazano je u tabelama 2 i 3 i grafikonima 1 i 2.

Tabela 1 - Proizvodnja, uvoz, izvoz i izvedena potrošnja plastičnih masa 2010-2016

Table 1 - Production, import, export and derived consumption of plastics 2010-2016

\begin{tabular}{|c|c|c|c|c|c|c|c|}
\hline & $\mathbf{2 0 1 0 .}$ & $\mathbf{2 0 1 1 .}$ & $\mathbf{2 0 1 2 .}$ & $\mathbf{2 0 1 3 .}$ & $\mathbf{2 0 1 4 .}$ & $\mathbf{2 0 1 5 .}$ & $\mathbf{2 0 1 6 .}$ \\
\hline Proizvodnja & 162.285 & 168.485 & 74.515 & 203.324 & 139.300 & 153.485 & 181.120 \\
\hline Uvoz, tone & 266.780 & 284.676 & 319.152 & 314.614 & 321.572 & 353.553 & 371.710 \\
\hline Izvoz, tone & 125.056 & 139.688 & 69.662 & 167.166 & 123.086 & 127.997 & 167.730 \\
\hline $\begin{array}{c}\text { Potrošnja, } \\
\text { tone }\end{array}$ & 304.010 & 313.473 & 324.035 & 350.771 & 337.787 & 379.041 & 385.100 \\
\hline
\end{tabular}

Izvor / Surce: UNDP, Vodič za smanjenje uticaja plastičnih proizvoda za jednokratnu upotrebu na životnu sredinu, Beograd, 2019.

Tabela 2 - Količina plastičnih kesa plasiranih na tržište Republike Srbije u 2016. godini

Table 2 - Quantity of plastic bags placed on the market of the Republic of Serbia in 2016

\begin{tabular}{|c|c|}
\hline Potrošnja kesa u svetu & Potrošnja kesa u Srbiji \\
\hline 10.000 .000 po satu & 292.000 po satu \\
\hline 240.000 .000 dnevno & 7.000 .000 dnevno \\
\hline 87.600 .000 .000 godišnje & 2.500 .000 .000 godišnje \\
\hline
\end{tabular}

Tabela 3 - Upotreba plastičnih kesa u Republici Srbiji u 2016. godini

Table 3 - Use of plastic bags in the Republic of Serbia in 2016

\begin{tabular}{|l|c|}
\hline & Ukupna količina izražena u tonama \\
\hline Plastične kese sa aditivima & 6862,6 \\
\hline Plastične kese bez aditivima & 203,6 \\
\hline Ukupno & 7066,2 \\
\hline
\end{tabular}

Izvor / Source: Agencija za zaštitu životne sredine, Plastične kese u Republici Srbiji u 2016. godini, Beograd, 2017, str. 10. 
Plastične kese izgledaju bezazleno, ali su opasne po životnu sredinu. Lagane su, pa ih vetar lako raznosi na velike udaljenosti i ima ih sve više. $U$ prirodi ostaju godinama, cepkajući se na sitne komade, a nikada ne nestaju u potpunosti. Pod uticajem UV zraka plastika se raspada na sve manje i manje komade, i većina plastike u okeanima su čestice manje od $5 \mathrm{~mm}$ i lakše od $1 \mathrm{~g}$, one predstavljaju „plastičnu supu“ koja pluta na dubini od 100 metara. Plutajuće plastične čestice privlače perzistentne organske zagađivače iz okolne vode i ostaju blizu površine gde in morske životinje mogu progutati $\mathrm{i}$ uneti u lanac ishrane. Osim toga, 100.000 životinja godišnje umre od gušenja plastičnim kesama, jer ih greškom uzmu kao hranu, a mnoge od njih se „upetljaju" u kese i ne mogu da se oslobode.

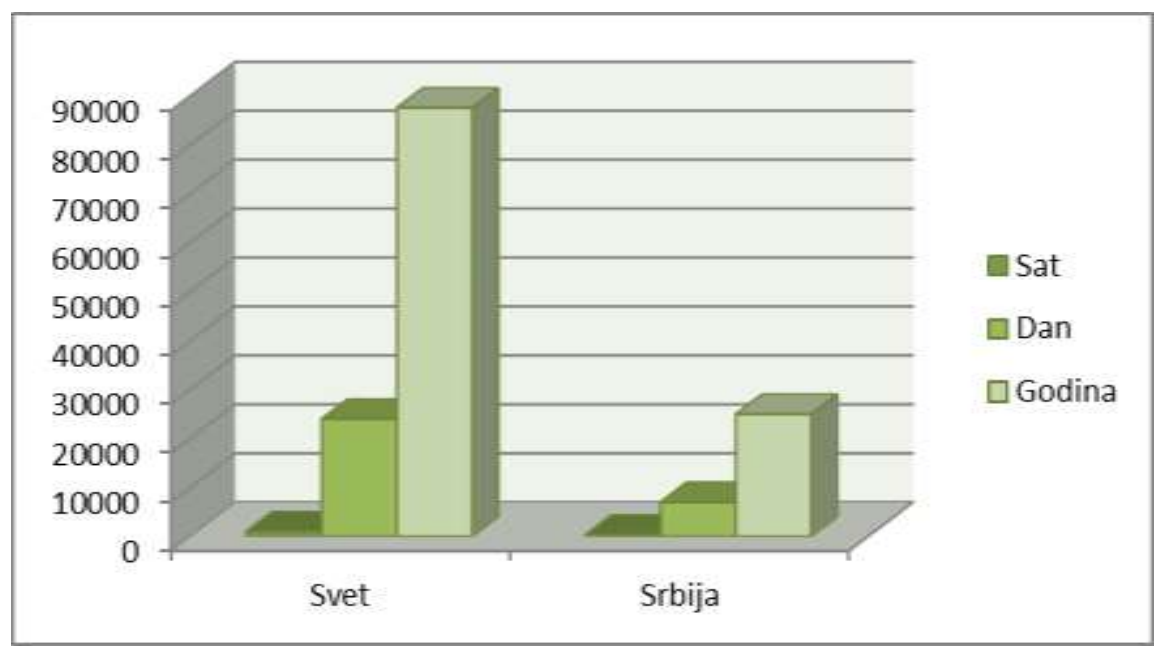

Grafikon 1 - Komparativni prikaz upotrebe plastičnih kesa u svetu i u Srbiji Graph 1 - Comparative overview of the use of plastic bags in the world and in Serbia

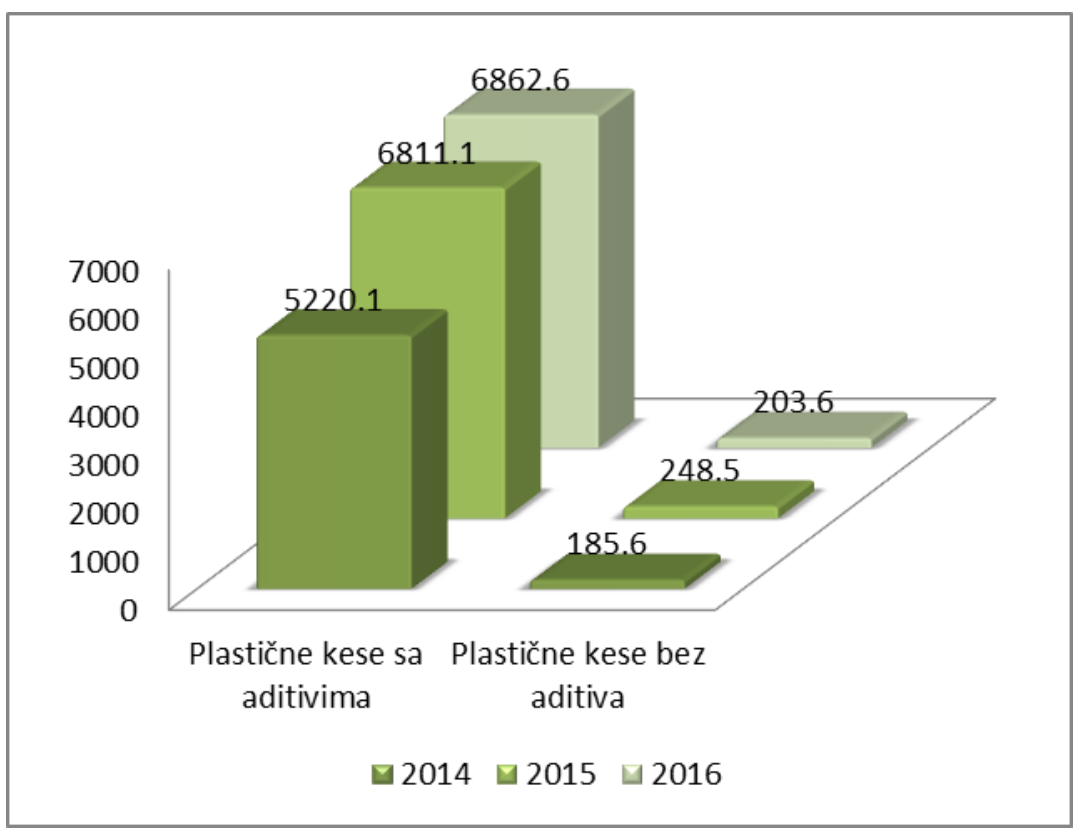

Grafikon 2 - Uporedni prikaz o plasiranim kesama na tržište Republike Srbije za period 2014-2016 Graph 2 - Comparative overview of bags placed on the market of the Republic of Serbia in 2014-2016 Izvor / Source: Agencija za zaštitu životne sredine, Plastične kese u Republici Srbiji u 2016. godini, Beograd, 2017, str. 11. 


\section{REZULTATI I DISKUSIJA /} RESULTS AND DUSCUSSION

Profesor Kasaš ističe da naši preci nisu imali otpad, postojalo je đubrište, ali oni nisu bili svesni šta se raspada biološki, a šta biohemijski. Odvojeno sakupljanje otpada, tj. primarna selekcija je osnova za postizanje ciljeva cirkularne ekonomije za plastiku (Kasaš, 2012). Najveće koristi od cirkularne ekonomije očekuju se na planu smanjena otpada čije se količine stalno uvećavaju. Primera radi, proizvedene količine plastike su narasle sa dva miliona tona godišnje (tokom pedesetih godina $X X$ veka) na skoro 380 miliona tona plastike koliko je proizvedeno u 2015. godini (Vuković i dr., 2020). Može li se danas naći proizvod bez plastike? Veoma teško. Čovek svakodnevno dolazi u kontakt sa više desetina predmeta od plastike, ali i sa svim dodacima koji omogućavaju da ona bude otpornija, elastičnija, tvrđa ili mekša. U Srbiji trenutno u sektoru plastike posluje ukupno 2.054 privrednih društava. Polovina od navedenog broja jesu izvoznici, a plastične proizvode plasiraju u više od 80 zemalja. Na osnovu podataka dostupnih kod Agencije za zaštitu životne sredine mogu se pratiti količine plastičnih kesa koje su plasirane na tržište Republike Srbije (UNDP, 2019). Plastične kese prave velike probleme u nerazvijenim i ruralnim sredinama, pri čemu su česti uzročnik brojnih zaraza. Naime, danas se o tome mora voditi posebno računa jer smo suočeni sa pandemijom Covid 19.

KNIToMANIA je preduzeće čija je osnovna ideja da se proizvodi prilagode tržištu i da se proširi svest o štetnom dejstvu jednokratne upotrebe plastičnih kesa. Cilj je pletenje proizvoda od iskorišćenih plastičnih kesa, pri čemu se spajaju tradicija i ekologija kako bi se zajedničkim biznisom doprinelo očuvanju životne sredine. Plastična kesa u ovom preduzeću može postati torba, ukras za jelku, privezak, predmet za čašu. U 2019. godini KNIToMANIA je iskoristila preko 7500 plastičnih kesa za rančeve, torbice i priveske:

- za ranac se upotrebi od 60 do 100 plastičnih kesa;

- za privezak se potroši minimum jedna kesa;

- za korpice se potroši minimum 10 kesa;

- osam baka se bavi heklanjem od kuće;

- za heklanje su potrebne heklice $3-3,5 \mathrm{~mm}$;

- ranac se "hekla" za okvirno 4 dana, a privesci u proseku po 7 dnevno;

- 180 rančeva je prodato za dve godine.

KNIToMANIA se zalaže za podizanje svesti zajednice na meanstream način, pri čemu ovo preduzeće ne rešava problem plastičnih kesa, već doprinosi promeni razmišljanja i perspektive ljudi. Poslovanje KNIToMANIE počiva na tri stuba: sprečavanje kesa da završe u prirodi, pomaganje starijim osobama da budu aktivnije u zajednici i da dodatno zarade i ohrabrivanje mladih da kontinuirano razmišljaju o novim idejama. Naravno, svest građana o zaštiti životne sredine se može povećati, $i$ to edukacijom, koja mora biti neformalna, ali istovremeno i inovativna i kreativna. Danas je vreme za nove inicijative i za preispitivanje šablona poslovanja koji su već ustaljeni.

Ako bi se napravila lokalna akcija prikupljanja kesa (beogradska, novosadska), a u zamenu za to spustila cena svih proizvoda KNIToMANIE, stvorila bi se mogućnost da se potencijalne pretnje po okolinu zadrže i ponovo upotrebe. Na ovaj način je moguće otvoriti već pomenuta zelena radna mesta, odnosno, zapošljavala bi se starija populacija kojoj je potrebna određena vrsta socijalne inkluzije.

\section{ZAKLJUČAK / CONCLUSION}

U Kruševcu živi 57.627 stanovnika (bez okoline), a od tog broja je $80 \%$ punoletno. Ako se pođe od informacija da u Srbiji prosečno domaćinstvo dnevno iskoristi 7 kesa, a u Kruševcu živi 19.342 domaćinstva, onda se prostom računicom dolazi do cifre od 135.394 plastičnih kesa koje se dnevno upotrebe u ovom gradu. Kada bi u Kruševcu prosečno domaćinstvo broj upotrebljenih plastičnih kesa smanjilo sa 7 na 3 , ostvarila bi se ušteda od $50 \%$, odnosno, od oko 100.000 kesa koje se upotrebljavaju dnevno, koristila bi se „samo“ polovina. Druga pretpostavka je da ukoliko se od 7 kesa bar 3 kese doniraju ovom perspektivnom preduzeću iz Kruševca, ostavlja se mogućnost da se proizvede još 1.500 rančeva, oko 1.000 privezaka, ali i da se angažuje još 15 do 20 starijih osoba, čime bi se proširili proizvodni kapaciteti.

Uzimajući u obzir da bi od početka ove godine jedinice lokalne samouprave trebalo da krenu u izradu i usvajanje novih lokalnih i regionalnih planova za upravljanje otpadom, a sve to uz očekivanja i planove koji idu uz Novi nacionalni plan, sada je pravi trenutak da se pokrene dijalog i razmena ideja o važnostima koje donosi orijentacija ka cirkularnoj ekonomiji na lokalnom nivou. Čuveni Ivan Turgenjev je rekao: „Reč „Sutra“ je izmišljena za decu i neodlučne ljude“.

\section{LITERATURA / REFERENCES}

[1] Arsić, Lj., Premović, J., Milićević, Z., Đokić, N., Stošić, N. (2020), Afirmacija modela cirkularne ekonomije u malim i srednjim preduzećima, Ecologica, 27(100), 647-653. 
[2] Bogetić, S., Đoršević D., Đorđević, Lj., Bakator, M. (2020), Analiza aspekta unapređenja životne sredine u procesu razvoja konkurentnosti, Ecologica, 27(97), 123-128.

[3] Cirkularna ekonomija kao šansa za razvoj Srbije, Misija OEBS-a u Srbiji, pristupljeno 23. januara 2021, na https://www.osce.org/sr/serbia/292311

[4] Findačevska, E., Gilev, J., Grujić, R., Jašić, M., Jokić, A., Zavargo, Z. (2015), Sustainable technologies, Tempus projekat, Novi Sad.

[5] Ghisellini, P., Cialani, C., Ulgiati, S. (2016), A review on circular economy: the expected transition to a balanced interplay of environmental and economic systems, Journal of Cleaner Production, 114, 11-32.

[6] GIZ, Upravljanje otpadom u kontekstu klimatskih promena (DKTI), pristupljeno 20. januara 2021, na

https://www.giz.de/en/downloads/CE\%20proc ena\%20efekata_Plasticna\%20ambalaza.pdf

[7] Janković, M., Ivannikov, N., Jovanović, L., Gajdobranski, A. (2020), Doprinos zelene ekonomije razvoju ekoturizma i organskoj proizvodnji, Ecologica, 27(98), 217-222.

[8] Jović Bogdanović A., Janković, M. (2019), Obezbeđenje sigurnosti $i$ održivosti životne sredine u gradovima i naseljima, Ecologica, 26(96), 449-454.

[9] Karolj, K., Protivnik plastičnim kesama, pristupljeno, 26. januar 2021, na http://www.gf.uns.ac.rs/zaposleni/kasas/Dr\%2 OKarolj\%20Kasas\%20prot\%20plast\%20kesa. pdf

[10] Kirchherr, J., Reike, D., Hekkert, M. (2017). Conceptualizing the circular economy: An analysis of 114 definitions. Resources, conservation and recycling, 127, 221-232.

[11] Mihajlović, D., Jovanović, V., Stojanović, D. (2020), Doprinos obnovljivih izvora energije razvoju zelene ekonomije i održive industrije, Ecologica, 27(98), 180-186.

[12] Ministarstvo zaštite životne sredine, Izveštaj o MSP i preduzetništvu, Beograd, 2018, pristupljeno 26. januar 2021, na

https://privreda.gov.rs/wpcontent/uploads/2019/01//zvestaj_MSPP_201 7.pdf

[13] Musu, I. (2010), Green Economy: great expectation or big illusion? Working Paper, No 01/ WP/2010, University of Venice, Department of Economics, Venice, pp. 11.

[14] Sébastien, S., Sophie, B., Pamela, S. (2015), Environmental sciences, sustainable development and circular economy: Alternative concepts for trans-disciplinary research, Department of Mathematics and Industrial Engineering, Canada.

[15] Topić, M., Biederman, H. (2015), Planning of integrated/sustainable solid waste management (ISAW) - Model of integrated solid waste management in Republika Srpska/B\&H. Serbian Journal of Management, 10 (2), 255-267.

[16] UNDP, (2019), Vodič za smenjenje uticaja plastičnih proizvoda za jednokratnu upotrebu na životnu sredinu, Beograd.

[17] Vinšalek Stipić, V. (2017), Cirkularna ekonomija kao pokretačza razvoj gospodarstva i smanjenje utjecaja krize. 10. Međunarodna znanstveno-stručna konferencija Dani kriznog upravljanja, 24-26. maj, 2017, Tuheljske Toplice, str. 722-734.

[18] Vukadinović, P. (2018). Ekologija između linearne i cirkularne ekonomije, Ecologica, 24(90), 231-236.

[19] Vuković, A., Riznić, D., Vuković, M. (2020), Cirkularna ekonomija u funkciji regeneracije prirodnih ekosistema, Ecologica, 27(98), 209216.

[20] Vuković, M., Štrbac, N., Urošević, S., Vuković, A. (2020), Razvoj koncepta cirkularne ekonomije u skaldu sa principima održivog razvoja, Ecologica, 27(98), 187-193.

[21] Živković, D., Petrović, P., Ercegović, M. (2020), Način finansiranja malih i srednjih preduzeća u hotelijerstvu i eko-turizmu, Ecologica, 27 (97), 75-81. 